CASE STUDY

\title{
EFFECT OF STRETCHING EXERCISES ON TRAPEZIUS WORKLOAD USING MVIC AS AN INDICATOR
}

\begin{abstract}
The substantial increase in using the desktop in offices is directly associated with Work Related Upper Limb Disorders (WRULDs) where an average workload on trapezius of 4 hours/day in females, is the main cause. Ergonomically inappropriate work station may increase the static muscle load at bilateral shoulder and wrist joint where keyboard is mostly responsible. Intermittent rest periods and varying positions are found significant during constant sedentary work. The aim of this study was to determine the effect of active stretching on the upper fibers of trapezius using desktop computer measured by MVIC.
\end{abstract}

A 22 years old left hand dominated female typing with an average frequency of 4 hours/day with 40 words/minute. An adjustable VDU was placed with arm, wrist and foot support. A word processing task was allotted for 20 minutes before and 20 min after the stretching. The Root Mean Square (RMS) for the EMG were collected at the intervals of 6th, 9th, 12th, 15th, and 18th minutes during typing. Subject performed three stretches of $20 \mathrm{sec}$ at the end followed by a rest period. The results reveal that resting EMG of the dominant hand was found to be $21 \%$ of MVIC where amplitude of EMG of the dominant hand is higher than the non-dominant (more than $10 \%$ higher). Stretching exercises decreased the activity of trapezius by $1.1 \%$ and the residual effect lasted for less than 12 minutes. It is suggested that 20 seconds of static stretching between the intervals were found to be effective in reducing the workload for the students. Studies on larger scales should be conducted for especially research and postgraduate students and proper workstations should be recommended for them.

\section{KEYWORDS}

MVIC (Maximum Voluntary Isometric Contraction), Work Related Upper Limb Disorders (WRULDs), workload, trapezius, stretching, EMG

\author{
Amna Aamir Khan \\ Assistant Professor \\ Ziauddin College of Physical Therapy \\ Ziauddin University \\ akhan39@caleodnian.ac.uk
}

[Khan AA. Effect of Stretching Exercises on Trapezius Workload Using MVIC as an Indicator. Pak. j. rehabil. 2017;6(2):51-53] 


\section{INTRODUCTION}

The transformation of manual working system into mechanical modern technology has increased many folds in the industry not only among the professionals but in students'. Paper and pen assignments has been taken over with workstations that has become an essential part of their activities of daily living ${ }^{2}$. These working stations are directly dependent on keyboard that is considered as one of the most common input devices for increasing the static muscle load at both wrist and shoulder joints. Insufficient muscle rest between the intervals and incorrect posture are considered as significant risk factors ${ }^{3}$. Prolong sitting and computer work for hours leads to poor posture where forward head position and protracted shoulder may be the cause of shoulder and neck pain 4 .

\section{Case}

A Healthy Postgraduate female student; aged 22 years was recruited that typed with an average frequency of 4 hours/day, since last 4 years. Left hand dominated with an average typing speed of 40 words/minute. The working table was adjusted such as; An adjustable Visual Display Unit (VDU), Adjustable chair with arm support, A wrist support, Document holder (placed on the right side as desired by the subject), Foot rest (for angles at hip and knee $=90^{\circ}$.

\section{METHOD}

Electrodes were placed on the upper trapezius of both the sides after fulfilling the criteria of EMG. A word processing task was allotted for 20minutes before and after the stretching period. Data was collected at a sampling rate of $1000 \mathrm{~Hz}$ at duration of 10 second. EMG at Rest and Maximum Voluntary Isometric Contraction (MVIC) was taken as baseline, and reference. The task was performed with a "start" clue. The Root Mean Square (RMS) for the EMG was collected at the intervals of 6th, 9th, 12th, 15th, and 18th min during typing. Subject performed three stretches of 20 second at the end. Small rest periods in between were allotted. The typing was started again with EMG taken at the same intervals.

\section{Observations}

A slouched posture was observed between the intervals of 12-15 minutes also showing a change in hip and knee angles at the similar intervals.

\section{RESULTS}

Resting EMG of the dominant hand was found to be
$21 \%$ of MVIC. It was also observed that the amplitude of EMG of the dominant hand is higher than the non-dominant (more than 10\% higher).

Stretching decreased the activity of trapezius by only $1.1 \%$ and the effect of stretching lasted for less than 12 minutes

\begin{tabular}{|l|c|c|c|}
\hline \multirow{2}{*}{} & \multicolumn{3}{|c|}{ TABLE - 1 } \\
\cline { 2 - 4 } & \multicolumn{3}{|c|}{ \% MVIC } \\
\cline { 2 - 4 } & \multicolumn{3}{|c|}{ Stretching (mean) } \\
\hline & resting & before & after \\
\hline dominant & 2 & 31.4 & 30.3 \\
\hline non- dominant & 5.9 & 15.0 & 12 \\
\hline
\end{tabular}

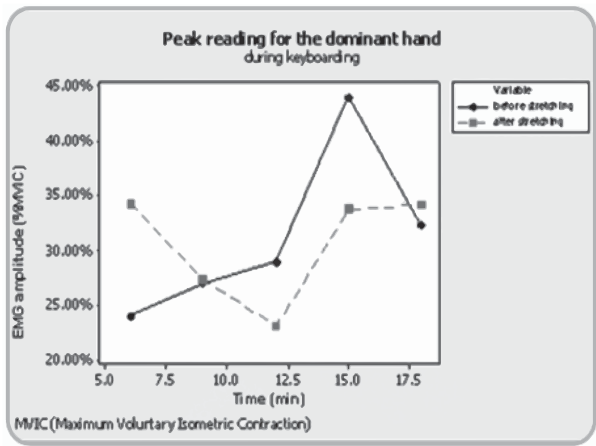

\section{Graph - 1}

Shows the effect of stretching for the dominant hand during typing

\section{DISCUSSION}

Results from this study agree with the study by Perk \& Yoo where a significant increase in the activity of trapezius was seen during keyboarding ${ }^{2}$. The results also indicate that an increase muscle workload on the shoulder/neck area of computer users that is nowadays similar to the research and postgraduate students'. Similar results were obtained when stretching of upper trapezius and levator scapulae were found to be more effective in decreasing muscle workload ${ }^{3}$. A study conducted by Page $P$ showed that static stretching improves stretch tolerance which ultimately increases the range of motion of the joint ${ }^{6}$.

Interestingly, static stretching is recommended to be sustained for 15-60 seconds but negative results were obtained when stretch was sustained for more than $30 \mathrm{sec}^{6}$. Unfortunately, a number of studies have already been conducted internationally but no study till date has been conducted in Pakistan considering MVIC for measuring the muscle strength. However, static stretching is considered as the most convenient, easy and frequently used treatment technique but the duration and frequency of stretching is still questionable. It is highly recommended that in future research needs to be conducted especially on young adults (university 
students) working more than 4 hours/day that may develop neck/shoulder problems while considering MVIC as an indicator.

\section{CONCLUSION}

As this case demonstrates, 20 seconds of static stretching between the intervals were found to be effective in reducing Work related upper limb disorders (WRULDS).

\section{REFERENCE}

[1] Atwal SS, Prasad A, Deepak D, Agarwal K. Health Issues among Radiologists: Toll they Pay to their Profession. J Clin Diagn Res. 2017; 11 (4):01-02.
[2] Park SY, Yoo WG. Effect of Sustained Typing Work on Changes in Scapular Position, Pressure Pain Sensitivity and Upper Trapezius Activity. J Occup Health. 2013;55(3):167-172

[3] Callegari B, Resende MM, Filho MS. Hand rest and wrist support are effective in preventing fatigue during prolonged typing. J Hand Ther. 2017;

[4] Bae WS et al. The effect of middle and lower trapezius strength exercises and levator scapulae and upper trapezius stretching exercises in upper crossed syndrome. J Phys Ther Sci. 2016; 28(5):

[5] Coppola SM. Evaluating Muscle Electromyography (EMG) In Females Across The Anthropometric Spectrum For Three Computer Input Device. Tufts University; 2015

[6] Page P. Current Concepts in Muscle Stretching For Exercise and Rehabilitation. Int J Sports Phys Ther. 2012;7(1):109-119 